\title{
Genetic screening of common genetic deafness in 60,391 women of childbearing age and intervention of birth defects
}

\section{Type}

Research paper

\section{Keywords}

genetic counseling, women of childbearing age, hereditary deafness genes, genetic screening

\begin{abstract}
Introduction

To analyze the carrying rate of common deafness gene variants in women of childbearing age in Weihai, and to probe into the feasibility of carrying out genetic screening for common genetic deafness in women of childbearing age to prevent deafness and birth defects via providing genetic counseling and follow-up services for high-risk families.

\section{Material and methods}

In total 60,391 pre-pregnancy/early-gestation women who received treatment in second-level or above hospitals in Weihai from February 2017 to December 2019 were selected. Venous or peripheral blood was collected to make dried blood slices on filter paper to extract genomic DNA, and high-throughput sequencing was applied to detect 20 variant sites in 4 common deafness genes (GJB2, GJB3, SLC26A4 and mitochondrial 12S rRNA) in the Chinese population. The spouses of women with deafness gene variants were sequenced.
\end{abstract}

\section{Results}

In total 3,761 carriers with deafness gene variants were detected in 6,0391 women of childbearing age, with a carrier rate of $6.2 \%$. Among them, 1,739 cases $(2.88 \%)$ only carried GJB2 pathogenic variants, 1,553 cases $(2.58 \%)$ only carried SLC26A4 pathogenic variants, 300 cases $(0.5 \%)$ only carried GJB3 variants, and 125 cases $(0.2 \%)$ carried mitochondrial drug-sensitive gene variant.

\section{Conclusions}

This screening model will greatly reduce the birth rate of children with hearing disabilities and is an effective way to prevent newborn with deafness. 
1 Genetic screening of common genetic deafness in 60,391 women of

2 childbearing age and intervention of birth defects

3

4

5

6

7

8

\section{Abstract \\ Objective}

At least $60 \%$ of severe hearing loss results from genetic factors. This study carried out genetic screening for common genetic deafness in women of childbearing age to prevent deafness and birth defects via providing genetic counseling and follow-up services for high-risk families.

\section{Material and Methods}

In total 60,391 pre-pregnancy/early-gestation women who received treatment in second-level or above hospitals in Weihai from February 2017 to December 2019 were selected. Venous or peripheral blood was collected to make dried blood slices on filter paper to extract genomic DNA, and high-throughput sequencing was applied to detect 20 variant sites in 4 common deafness genes (GJB2, GJB3, SLC26A4 and mitochondrial $12 S$ $r R N A)$ in the Chinese population. The spouses of women with deafness gene variants were sequenced.

\section{Results}

In total 3,761 carriers with deafness gene variants were detected in 60,391 women of childbearing age, with a carrier rate of $6.2 \%$. Among them, 1,739 cases $(2.88 \%)$ only carried GJB2 pathogenic variants, The carrying rate of c.235delC in GJB2 pathogenic variants was the highest at $2.08 \% .1,553$ cases $(2.58 \%)$ only carried SLC26A4 pathogenic 
23

variants, the carrying rate of c.919-2A $>$ G in SLC26A4 pathogenic variants was the highest at $1.63 \% .300$ cases $(0.5 \%)$ only carried GJB3 variants, and 125 cases $(0.2 \%)$ carried mitochondrial drug-sensitive gene variant.

\section{Conclusion}

This screening model will greatly reduce the birth rate of children with hearing disabilities and is an effective way to prevent newborn with deafness. In addition, genetic screening provided the related knowledge of hereditary deafness, especially strengthen genetic counseling and the clinical decision making from the genetic screening.

Keywords: hereditary deafness genes; women of childbearing age; genetic screening; genetic counseling

\section{Introduction}

Hearing loss is a universal auditory dysfunction. Severe hearing loss signally impacts human daily communication and social activities. Based on the latest WHO data in 2019, there are about 466 million hearing-impaired people worldwide, accounting for 5\% of the world's total population [1]. The Second National Sample Survey on Disabilities in 2006 revealed that there were 27.8 million people with hearing disabilities in China, of which 20.04 million were simply with hearing disabilities, accounting for $24.2 \%$ of the total [2]. Neonatal deafness incidence is $1-3 \%$, that is, about 30,000 deaf children are born every year. China Birth Defects Prevention Report (2012) pointed out that hearing disabilities have become the second largest birth defect in China. Therefore, preventing hearing 
disabilities and intervening birth defects are essential aspects to improve the quality of Chinese population. Studies have shown that at least $60 \%$ of severe hearing loss results from genetic factors [3]. The hereditary hearing loss mainly involves four types: autosomal recessive inheritance (approximately 80\%), autosomal dominant inheritance (approximately 15\%-20\%), mitochondrial inheritance (approximately 1\%) and sex-linked Inheritance (approximately 1\%) [4]. Based on the molecular epidemiological survey of deafness in China, GJB2, GJB3, SLC26A4 and mitochondrial $12 S$ rRNA are the most universal deaf genes in Chinese[5,6]. The hereditary hearing loss resulting from GJB2 and SLC26A4 follows autosomal recessive inheritance. Carriers of mitochondrial $12 S$ rRNA variants are sensitive to aminoglycoside drugs, belonging to maternal inheritance, whose deafness rate in Chinese with hearing loss is up to $34 \%$ [5]. However, survey data reveal that among the normal population in China, about $6 \%$ are carriers of common deafness gene variants $[7,8]$, and most of deaf newborn each year are born from families without a family history of deafness. It can be seen that although deafness gene screening and intervention for people with hearing loss can prevent deaf birth by deaf parents to a certain extent, it cannot effectively prevent the normal parents from giving birth to children with hereditary hearing loss. Therefore, screening of common deafness genes in normal population before marriage check or pregnancy and early gestation, early detection of couples with pathogenic variants in the same gene and corresponding intervention measures are effective means to prevent hearing disabilities.

In this study, we conducted common deafness gene screening on 60,391 women of childbearing age in Weihai, genetic counseling on high-risk families and corresponding 
intervention measures, which can effectively prevent these families from giving birth to children with hearing loss, thus reducing the incidence in the region and provide genetic counseling and the clinical decision making from the genetic screening.

\section{Subjects and methods}

\subsection{Research subjects}

In total 60,391 pre-pregnancy/early-pregnancy women receiving treatment in second-level or above hospitals in Weihai between February 2017 and December 2019 were selected, ranging in age from 18 to 47 , and gestational age less than 15+6 weeks. Among them, in total 53 cases with different degrees of hearing loss, and 17 with family history of hearing disabilities. This work was approved by the Medical Ethics Committee of Weihai Maternal and Child Health Hospital, and all research subjects signed informed consent forms.

All patients completed the survey by answering questions and filling in the "deafness questionnaire survey form." The details were as follows: (a) basic information: name, gender, date of birth, nationality, marital status, contact information, etc.; (b) morbidity status: age of onset, presence of other associated symptoms (vertigo, tinnitus, etc.), related medical history (infectious diseases, etc.), history of use of aminoglycoside antibiotics, long-term noise exposure, otitis media or traumatic history of the ear, etc.; (c) the development condition of language, whether wearing hearing aid or cochlea, etc.; and (d) whether merging other systemic diseases (eyes, bones, intelligence, etc.).Ear examination and audiological evaluations including pure-tone audiometry, immittance testing, auditory brainstem response, and auditory steady - state response were performed for all hearing impairment patients. Physical and neurological examination was carried out with special attention to renal and ophthalmologic differences to exclude those with syndromic deafness. 
(Figure1 Research processes)

\subsection{Methods}

\subsubsection{DNA extraction}

Venous or peripheral blood of our subjects were collected to prepare dry blood slices on filter papers (Whatman 903), each with at least 2 blood spots. An automatic punching machine was used to take a slice of dried blood sample to corresponding 96-well plates complemented with reagents, and sealed it with aluminium film.. The plates were placed on the warm heater to boil, and cooled for later use. QIAamp DNA Blood Mini Kit (Qiagen, Germany) was used to extract genomic DNA from each blood sample following the manufacturer's instructions, and NanoDrop 2000 Spectrophotometer (Thermo Fisher Scientific, Waltham, MA) was used to evaluate the quantity and quality of extracted DNA.

\subsubsection{Library construction}

Twenty common variant sites of GJB2, SLC26A4, and GJB3, as well as $m t D N A$, were detected by using a deafness diagnostic screening panel (CapitalBio Genomics Co., Ltd., China). Library construction, quality control, and sequencing template preparation were performed according to the instructions of a Blood DNA LQ kit. PCR method was used to amplify 20 variant sites in GJB2, GJB3, SLC26A4 and mitochondrial $12 S$ rRNA genes, then sequencing labels were added and purified to complete library construction..

\subsubsection{Deafness gene detection}

Via high-throughput sequencing method and gene sequencer BGISEQ-500 to detect deafness genes, 20 pathogenic sites in 4 genes were detected, including in GJB2 c.35delG, 
c.167delT, c.176_191del16, c.235delC and c.299_300delAT, GJB3 gene c.538C>T and c. $547 \mathrm{G}>\mathrm{A}$, in $S L C 26 A 4$ c. $281 \mathrm{C}>\mathrm{T}$, c.589G $>\mathrm{A}$, c.919-2A>G, c. $1174 \mathrm{~A}>\mathrm{T}$, c. $1226 \mathrm{G}>\mathrm{A}$, c. $1229 \mathrm{C}>\mathrm{T}$, c. $1707+5 \mathrm{G}>\mathrm{A}$, c. $1975 \mathrm{G}>\mathrm{C}$, c. $2027 \mathrm{~T}>\mathrm{A}, \mathrm{c} .2162 \mathrm{C}>\mathrm{T}$ and c. $2168 \mathrm{~A}>\mathrm{G}$, and in mitochondrial $12 S$ rRNA $\mathrm{m} .1494 \mathrm{C}>\mathrm{T}$ and $\mathrm{m} .1555 \mathrm{~A}>\mathrm{G}$.

For women who have been screened for the pathogenic sites in deafness genes, it is recommended that their spouses carry out corresponding gene sequencing, providing medication guidance for women with drug-sensitive gene variants. For couples who carry pathogenic variants in the same gene, providing genetic counseling and corresponding intervention measures were taken. Postpartum neonatal hearing screening and follow-up for women with deafness gene mutations were done.

\section{Results}

\subsection{Deafness gene screening results of 60,391 cases}

Among 60,391 pre-pregnancy/early-pregnancy women, in total 3,761 women carried common deafness gene variants, with a total carrier rate of $6.23 \%(3,761 / 60,391)$ (Table 1), $1724(2.85 \%)$ carried only one GJB2 variant, $1,534(2.54 \%)$ only carried one SLC26A4 variant, $300(0.5 \%)$ only carried one GJB3 variant, and $125(0.2 \%)$ carried drug-sensitive gene variation. There were 44 women $(0.07 \%)$ carrying two deafness gene variants, of which 38 carried both GJB2 and SLC26A4 variants, accounting for $0.06 \%$ of the total screened population, 3 carried both GJB2 and GJB3 variants, and 3 carried SLC26A4 and GJB3 variants at the same time. Additionally, 53 cases with clinical manifestations of 
varying degrees of hearing loss, of which $15(0.02 \%)$ carried 2 pathogenic variants in GJB2 at the same time, $19(0.03 \%)$ carried 2 pathogenic variants in SLC26A4 at the same time, 3 carried gene variants for drug-sensitive deafness, 4 only carried 1 variant in $G J B 2$ or SLC26A4, and 12 did not carry common variants.

GJB2. In this work, 1,780 cases carried GJB2 variant, with a carrying rate of $2.92 \%$ (1,780/60,391). Among them, the carrying rate of c.235delC was the highest at $2.08 \%$; c.299_300delAT was the second with $0.73 \%$; the carrying rate of c.35delG was the lowest at $0.005 \%$ (Table 2).

SLC26A4. In total 1,594 cases carried SLC26A4 variant, with a carrying rate of $2.62 \%$ (1,594/60,391). Among them, the carrying rate of c.919-2A>G was the highest at $1.63 \%$, followed by c. $2168 \mathrm{~A}>\mathrm{G}$, with a carrying rate of $0.42 \%$ (Table 3 ).

\subsection{Deafness gene sequencing results of spouses}

Based on the female test findings, we recommend that the husbands of 3,336 women with GJB2 or SLC26A4 variants carry out corresponding gene sequencing. In total 1,746 women's spouses agreed to be tested. The detection rate was 52.3\% (1746/3336) and 139 cases carrying GJB2 or SLC26A4 variants, with a carrying rate of $7.96 \%(139 / 1,746)$. Among them, 1,146 cases were sequenced for GJB2, 77 carrying known pathogenic variants, and 5 carrying suspected pathogenic variants or variants of unknown clinical significance. In total 600 cases were sequenced for SLC26A4, 31 carrying known pathogenic variants, and 26 carrying suspected variants or variants of unknown clinical significance. From the results, the known pathogenic variants were mainly c.109G>A (2.18\%), c.235delC (1.54\%), c.299_300delAT (0.52\%) and c.919-2A> in SLC26A4 and G 
$(0.98 \%)$ in GJB2. At the same time, in SLC26A4 suspected pathogenic variants and variants of unknown clinical significance accounted for a relatively high proportion of $1.49 \%$ (Table 4).

\subsection{Results of fetus receiving prenatal diagnosis}

Based on the clinical manifestations and test results of couples, it was finally determined that 99 couples carried known or suspected pathogenic variants in GJB2 or SLC26A4, and their offspring have a $25 \%$ risk of disease, which is in line with the prenatal indications for diagnosis. But among these 99 couples, 38 husbands carried GJB2 c.109G>A variant. At present, although GJB2 c.109G>A variant is considered to be a pathogenic variant, the hearing phenotype resulting from it is quite different: hearing can be normal or weakened, and it also can be manifested at birth or later, so if the offspring is diagnosed as $G J B 2$ c.109G $>$ A homozygous variant or compound heterozygous variant before birth, their hearing phenotype after birth cannot be predicted. Finally, after genetic counseling and full informed consent, in total 51 couples underwent prenatal diagnosis, including 6 with GJB2 c.109G>A variant (Table 5), and 7 chose to do pre-implantation genetics diagnosis. The results of prenatal diagnosis showed that the offspring of 14 couples inherited deafness gene variants other than $G J B 2$ c.109G $>$ A from their parents. It is most likely that they are hereditary deafness patients, accounting for $27.5 \%$. The offspring of 2 couples were GJB2 c.235delC/c.109G>A compound heterozygous variant and c.109G>A/c.299_300delAT compound heterozygous variant. The offspring of 23 couples may carry only one deaf gene variant or they did not inherit variants of their parents, and the predicted risk of the fetus with hereditary deafness is extremely low. 
186

187

homogenous variants, 21 carried $12 S$ rRNA $1555 \mathrm{~A}>\mathrm{G}$ heterogeneous variants, and 7 carried $12 S$ rRNA 1494C>T homogenous variants (Table 1), respectively, accounted for $0.16 \%$, $0.03 \%$ and $0.01 \%$ of the total people screened. The follow-up of women and their maternal family members found that 3 cases were with hearing disability and 1 uncle with hearing disability. Because drug-susceptibility gene mutations follow the maternal inheritance method, we issued medication guide cards to 125 carriers of drug-susceptibility gene mutations, informing them and their maternal family members that they should absolutely avoid using aminoglycoside drugs throughout their lives to in case of deafness.

\subsection{The follow-up results of the offspring's hearing}

Our work conducted follow-up of the offspring's hearing of 3,761 female carriers, 21 cases' children were finally diagnosed as hearing disabilities.

Among them, 18 children were tested for deafness genes, 12 carried two variants in GJB2 or $S L C 26 A 4$, and they were clearly children with congenital hereditary hearing loss; 6 cases did not carry or only carried one variant in GJB2 or SLC26A4 (Table 6).

\section{Discussion}

GJB2 variant is the first cause of hereditary nonsyndromic hearing loss (NSHL) among Chinese. At present, there are more than 100 gene variants in $G J B 2$ that are known to be pathogenic (https://hereditaryhearingloss.org.), and these variants have obvious regional and ethnic differences [9]. There are also differences in common GJB2 variant sites in Chinese from different regions.[10]. SLC26A4 is the second most universal variant gene in 
NHSL patients, and patients of different races also have different gene variant profiles[11-13]; In China, c.919-2A>G is the most common variant [14]. Based on previous studies, in our hospital the main pathogenic variant of NSHL patients in Jiaodong area is GJB2 c.235delC, followed by SLC26A4 c.919-2A>G [15]. Among 60,391 women of childbearing age in this work, 1,739 only carried GJB2 variant, with a carrying rate of $2.88 \% ; 1,553$ cases only carried SLC26A4 variant, with a carrying rate of $2.58 \%$. The carrying rates of GJB2 and SLC26A4 variants among Chinese were $3 \%$ and 2-3\%, respectively, which are basically the same [7, 8]. Among them, GJB2 c.235delC has the highest carrying rate, accounting for $2.08 \%$; followed by SLC26A4 c.919-2A>G, with a carrying rate of $1.63 \%$, which further confirms that common deafness gene variants in Jiaodong are mainly GJB2 c.235delC and $S L C 26 A 4$ c. 919-2A $>$ G.

GJB2 encodes a gap junction protein (Connexin26 protein, Cx26).[16]. The most common pathogenic variant in GJB2 among Chinese is c.235delC, if which lack its base will result in frameshift variants in the coding region of $G J B 2$, leading to premature termination of translation and the formation of non-functional $\mathrm{Cx} 26$, which results in sensorineural hearing loss [17]. GJB2 c.235delC homozygous variant is mostly manifested as congenital severe-extremely severe hearing loss, and very few are delayed moderate post-lingual hearing loss [18]. Guo Chang et al. [19] conducted audiometric phenotype statistics on 100 NSHL patients with GJB2 c.235delC homozygous variant, finding that patients with deafness caused by GJB2 c.235delC homozygous variant showed diversity in both ear hearing phenotypes and the degree of hearing loss are mainly extremely severe, severe and moderately severe, whereas mild is the least common. In this work, 6 women were detected 
as GJB2 c.235delC homozygous variant, and their hearing phenotypes were also heterogeneous, including 4 cases with congenital extremely severe hearing loss in both ears, 1 case with moderate hearing loss, and 1 case with mild hearing loss. This has accumulated original data for us to further exploit the mechanism of different hearing phenotypes of patients carrying the same gene variants, thereby providing a possible basis for treating genes in NHSL patients.

In 2013, Dai Pu et al. [20] proposed a tertiary prevention strategy for hearing disabilities of birth defects based on genetic screening and diagnosis. First, via drug-induced deafness susceptibility screening, fertility guidance for deaf couples, early-pregnancy general screening, pre-love guidance for young deaf people to achieve primary prevention; second, through prenatal diagnosis and intervention to achieve the secondary prevention; third, through neonatal gene screening to achieve the tertiary prevention. At present, the joint screening of neonatal hearing and deafness genes has been widely promoted in China and has achieved certain findings. A number of studies have shown that $[21,22]$ hearing combined with deafness gene screening is an effective means for early detecting late-onset hereditary hearing loss and drug-sensitive individuals. It provides opportunities for early treatment and lingual rehabilitation for children, with important clinical significance.

In this work, 60,391 women of childbearing age were screened for common deafness genes. With the actual detection rate of spouses being 52.3\%, 99 high-risk families were finally identified. After genetic counseling, 7 families opted for preimplantation genetic diagnosis, and 51 families for prenatal diagnosis. The findings of prenatal diagnosis showed that 14 fetuses were most likely to have hearing loss, and the diagnosis rate was $27.5 \%(14 / 51)$. It 
252

253

can be seen that carrying out common deafness genetic screening among women of childbearing age and providing follow-up services such as genetic counseling for high-risk families is greatly essential for reducing birth defects with hearing disabilities.

In our practice of screening common deafness genes in women of childbearing age in this region, we have summarized the following experiences:

1. Common deafness gene screening is highly accepted among women of childbearing age in this region. On average, more than $90 \%$ of pre-pregnancy/early-pregnancy women are voluntarily tested each year. In addition to publicity and education, government departments also played an important role in including the testing project in people's livelihood to implement free testing. It can be seen that the government departments provide strong support for preventing and controlling birth defects in terms of policies and funds, which effectively promotes the prevention and control of birth defects in the region. 2. The rate of further testing for the spouses of female carriers is low $(52.3 \%)$, which is far lower than that of females, especially in SLC26A4 sequencing, only $37.6 \%$ (600/1594). After analysis, the first reason is that most families believe that the hearing of both parents is normal, with no family history of hearing disabilities and that the probability that both couples carry the same type of deaf gene variant is very low, with fluke mind. Second, the cost for spouse's receiving corresponding gene sequencing is relatively high and needs to be borne by themselves. if these families were highly compliant with our recommendation at that time, through genetic counseling and prenatal diagnosis, we could at least predict the hearing status of the offspring in $47.6 \%$ (10/21) of families and provide them with the 
273

274

opportunity to choose. Therefore, how to improve the general people's correct understanding of hereditary deafness is a problem that we urgently need to solve.

3. Be cautious about genetic counseling of controversial pathogenic variants. The detection rate of $G J B 2$ c. $109 \mathrm{G}>\mathrm{A}$ variant is relatively high in both normal people and patients with hearing disabilities. Existing research statistics show that c.109G > A is a pathogenic variant, but the hearing phenotypes caused by it are quite different: hearing can be normal or weakened, and the degree of hearing loss can range from mild to severe. This work finally determined that in families where both couples carry known pathogenic variants in the GJB2 gene, 38 husbands are carriers of c.109G>A. With full knowledge, 6 families chose prenatal diagnosis, and finally 2 families had fetuses with c.109G>A compound heterozygous variant ( 1 case was c.109G>A/c.299_300delAT compound heterozygous variant; 1 case was c.235delC/c.109G>A compound heterozygous variant). We followed up the hearing of their offspring, and both families indicated that their offspring had passed the newborn hearing screening. Because the later clinical manifestations of this group of people are unpredictable, we recommend that the two families undergo regular hearing monitoring to accurately assess their hearing level.

4. Although hearing impairment is not a serious disability or death disease, it will seriously affect the quality of life and bring a heavy economic and spiritual burden to families. In this work, prenatal diagnosis was applied to predict that 14 fetuses were likely to have hearing loss. We learned from follow-up that 12 of them chose to terminate pregnancy and suggested that these families should give priority to preimplantation genetics if they have reproductive needs. Diagnosis to prevent the occurrence of hereditary deafness. Therefore, 
295

296

297

with continuously advancing society and generally improved awareness, realizing primary prevention of birth defects of hearing disabilities, that is, to carry out genetic screening for hereditary deafness before pregnancy or even before marriage, and actively adopt corresponding intervention measures, will more effectively avoid various economic and social ethical issues.

\section{Conclusion}

Screening for common deafness genes in women of childbearing age and providing follow-up consultation and diagnosis are effective means to prevent birth deafness. Such screening mode is available to realize early diagnosis and intervention of hereditary deafness, providing families with an opportunity to make informed choices. It can also warn those carrying drug-sensitive deafness genes to avoid using ototoxic drugs in case of hearing loss. But it is still necessary to further promote the publicity and education of deafness gene screening, popularizing the related knowledge of hereditary deafness, especially to strengthen genetic counseling for high-risk families, so that they have a clearer understanding of hereditary deafness, are more willing to receive deafness gene testing, and further understand the importance of preimplantation genetic diagnosis or prenatal diagnosis to prevent hereditary deafness. Additionally, the government's strong support for preventing and controlling birth defects will also encourage more people to receive test to a certain extent.

\section{Acknowledgments}


Not applicable.

\section{Declaration of Conflicting Interests}

The author(s) declared no potential conflicts of interest with respect to the research, authorship, and/or publication of this article.

\section{Authors' contributions}

Linyuan Niu designed the research study. Liqin Liu performed the research. Jinjun Tian provided help and advice on the experiments. Wei Chen and Chunxiao Zhang analyzed the data. Linyuan Niu and Xinqiang Lan wrote the manuscript. All authors contributed to editorial changes in the manuscript. All authors read and approved the final manuscript.

\section{References:}

1. WHO Estimates. [(accessed on 29 December 2019)]; Available online: http://www.who.int/deafness/estimates/en/

2. Office of the Second Sample Survey of Disabled Persons, Main Data Manual of the Second National Sample Survey of Disabled Persons. Beijing. Huaxia Publishing House, 2007. 2(38).

3. Van Camp, G., P.J. Willems, and R.J. Smith, Nonsyndromic hearing impairment: unparalleled heterogeneity. Am J Hum Genet. 1997. 60(4): p. 758-64.

4. Ma Y, Wise AK, Shepherd RK, et al. New molecular therapies for the treatment of hearing loss. Pharmacol Ther. 2019;200:190-209.

5. Yuan Y, You Y, Huang D, et al., Comprehensive molecular etiology analysis of nonsyndromic hearing impairment from typical areas in China. J Transl Med. 
2009;7:79.

6. Zhao P, Lin L, Lan L. Analysis of mutation spectrum of common deafness-causing genes in Hakka newborns in southern China by semiconductor sequencing. Medicine (Baltimore). 2018;97(38):e12285.

7. Yu F, GJB2 mutation screening and full-spectrum mutation mapping in patients with non-syndromic deafness. 2006, PLA Academy of Continuing Military Medical Sciences.

8. Yuan YY, Molecular Epidemiology and Pathogenic Mechanism Research on Chinese Severe-Extreme Deafness. 2007, PLA Academy of Continuing Medical Sciences.

9. Putcha GV, Bejjani BA, Bleoo S, et al., A multicenter study of the frequency and distribution of GJB2 and GJB6 mutations in a large North American cohort. Genet Med. 2007. 9(7): p. 413-426.

10. Dai P, Yu F, Han B, et al., GJB2 mutation spectrum in 2063 Chinese patients with nonsyndromic hearing impairment. J Transl Med. 2009;7:26.

11. Zheng J, Shen W, He DZ, et al., Prestin is the motor protein of cochlear outer hair cells. Nature, 2000. 405(6783): p. 149-155.

12. Tsukamoto K, Suzuki H, Harada D, et al., Distribution and frequencies of PDS (SLC26A4) mutations in Pendred syndrome and nonsyndromic hearing loss associated with enlarged vestibular aqueduct: a unique spectrum of mutations in Japanese. Eur J Hum Genet. 2003;11(12):916-922.

13. Shin JW, Lee SC, Lee HK, et al., Genetic Screening of GJB2 and SLC26A4 in 
Korean Cochlear Implantees: Clin Exp Otorhinolaryngol. Clinical \& Experimental Otorhinolaryngology, 2012. 5(Suppl 1): p. S10-S13.

14. Oliver D, He DZ, Klöcker N, et al., Intracellular Anions as the Voltage Sensor of Prestin, the Outer Hair Cell Motor Protein. Science, 2001. 292(5525): p. 2340-2343.

15. Sun SY, Mutation analysis of GJB2, SLC26A4, GJB3 and $12 S$ rRNA in non-syndromic deafness patients in Jiaodong area. Chinese Journal of Medical Genetics, 2019;36(5):433-438.

16. Todt I, Hennies HC, Basta D, Vestibular dysfunction of patients with mutations of Connexin 26. Neuroreport, 2005;16(11):1179-1181.

17. Friedman T, Battey J, Kachar B, et al., Modifier genes of hereditary hearing loss. Current Opinion in Neurobiology, 2000. 10(4): p. 487-493.

18. Zhao FF, Ji YB, Wang DY., et al., Phenotype-genotype correlation in 295 Chinese deaf subjects with biallelic causative mutations in the GJB2 gene. Genet Test Mol Biomarkers., 2011;15(9):619-625.

19. Guo Chang, et al., Hearing phenotype analysis of deaf patients caused by GJB2 235delC homozygous mutation. Chinese Journal of Otology, 2018. 16(02): p. 165-170.

20. Dai Pu and Yuan Yongyi, Tertiary prevention of birth defects with deafness based on genetic screening and diagnosis. Chinese Journal of Otorhinolaryngology-Head and Neck Surgery, 2013. 48(12): p. 973-977.

21. Wang Q, Xiang J, Sun J, et al., Nationwide population genetic screening improves 
outcomes of newborn screening for hearing loss in China. Genet Med. 2019;21(10):2231-2238.

22. Guo L, Xiang J, Sun L, et al., Concurrent hearing and genetic screening in a general newborn population. Hum Genet 2020. 139(4): p. 521-530.

Table 1 Common deafness gene screening results of 60,391 cases

\begin{tabular}{|c|c|c|c|}
\hline Variant types & Cases & $\begin{array}{l}\text { Carrying rate } \\
\qquad(n=3761)\end{array}$ & $\begin{array}{l}\text { Carrying rate } \\
(n=60391)\end{array}$ \\
\hline $12 S$ rRNA $1555 \mathrm{~A}>\mathrm{G}$ homogenous variant & 97 & $2.58 \%$ & $0.16 \%$ \\
\hline $12 S$ rRNA $1555 \mathrm{~A}>\mathrm{G}$ heterogenous variant & 21 & $0.56 \%$ & $0.03 \%$ \\
\hline $12 S r R N A 1494 C>\mathrm{T}$ homogenous variant & 7 & $0.19 \%$ & $0.01 \%$ \\
\hline GJB2 homozygous variant & 9 & $0.24 \%$ & $0.01 \%$ \\
\hline GJB2 compound heterozygous variant & 6 & $0.16 \%$ & $0.01 \%$ \\
\hline SLC26A4 homozygous variant & 5 & $0.13 \%$ & $0.01 \%$ \\
\hline SLC26A4 compound heterozygous variant & 14 & $0.37 \%$ & $0.02 \%$ \\
\hline Total 1 & 159 & $4.23 \%$ & $0.26 \%$ \\
\hline GJB2 heterozygous variant & 1724 & $45.84 \%$ & $2.85 \%$ \\
\hline SLC26A4 heterozygous variant & 1534 & $40.79 \%$ & $2.54 \%$ \\
\hline
\end{tabular}


$\begin{array}{llll}\text { GJB3 compound heterozygous variant } \quad 300 \quad 7.98 \% & 0.50 \%\end{array}$

Combined heterozygous variants in GJB2 and $\quad 38 \quad 1.01 \% \quad 0.06 \%$

$$
\text { SLC26A4 }
$$

Combined heterozygous variants in GJB2 and $3 \quad 0.08 \% \quad 0.005 \%$

GJB3

Combined heterozygous variants in SLC26A4 $3 \quad 0.08 \% \quad 0.005 \%$

and $G J B 3$

\begin{tabular}{cccc}
\hline Total 2 & 3602 & $95.77 \%$ & $5.96 \%$ \\
\hline Total (1+2) & 3761 & $100.00 \%$ & $6.23 \%$ \\
\hline
\end{tabular}

391 Note: The statistical results do not include polymorphic sites in gene.

392

Table 2 Statistics of GJB2 variant types

\begin{tabular}{cccc}
\hline Variant types & Variant sites & Cases & Carrying rate \\
& & & $(\mathrm{n}=60391)$ \\
\hline Homozygous variant & c.235delC & 6 & $0.01 \%$ \\
Heterozygous variant & c.299_300delAT & 3 & $0.005 \%$ \\
& c.176_191del16 & 65 & $0.11 \%$ \\
& c.235delC & 1257 & $2.06 \%$ \\
& c.35delG & 440 & $0.72 \%$
\end{tabular}



Compound
c.176_191del16/c.235delC
$10.002 \%$

heterozygous variant

\begin{tabular}{|c|c|c|c|}
\hline & c.235delC/c.299_300delAT & 5 & $0.01 \%$ \\
\hline Total & & 1780 & $2.92 \%$ \\
\hline
\end{tabular}

393 Note: This statistical data contains 41 cases that carry both GJB2 and other deafness gene 394 variants.

Table 3 Statistics of SLC26A4 variant types

\begin{tabular}{cccc}
\hline Variant types & Variant sites & Cases & $\begin{array}{c}\text { Carrying rate } \\
(\mathrm{n}=60391)\end{array}$ \\
\hline Homozygous variant & c. $1229 \mathrm{C}>\mathrm{T}$ & 1 & $0.00 \%$ \\
c. $919-2 \mathrm{~A}>\mathrm{G}$ & 4 & $0.01 \%$ \\
& c. $1174 \mathrm{~A}>\mathrm{T}$ & 114 & $0.19 \%$ \\
& c. $1226 \mathrm{G}>\mathrm{A}$ & 46 & $0.08 \%$ \\
& c. $1229 \mathrm{C}>\mathrm{T}$ & 75 & $0.12 \%$ \\
& & 136 & $0.23 \%$
\end{tabular}




$\begin{array}{ccc}\text { c. } 2027 \mathrm{~T}>\mathrm{A} & 31 & 0.05 \% \\ \mathrm{c} .2168 \mathrm{~A}>\mathrm{G} & 248 & 0.41 \% \\ \mathrm{c} .281 \mathrm{C}>\mathrm{T} & 5 & 0.01 \% \\ \mathrm{c} .589 \mathrm{G}>\mathrm{A} & 27 & 0.04 \% \\ \mathrm{c.} 1707+5 \mathrm{G}>\mathrm{A} & 16 & 0.03 \% \\ \mathrm{c} .919-2 \mathrm{~A}>\mathrm{G} & 877 & 1.45 \%\end{array}$

Compound

c. $1174 \mathrm{~A}>\mathrm{T} / \mathrm{c} .1226 \mathrm{G}>\mathrm{A}$

1

$0.002 \%$

heterozygous variant

\begin{tabular}{ccc} 
c. $919-2 \mathrm{~A}>\mathrm{G} / \mathrm{c} .1174 \mathrm{~A}>\mathrm{T}$ & 2 & $0.003 \%$ \\
$\mathrm{c} .919-2 \mathrm{~A}>\mathrm{G} / \mathrm{c} .1226 \mathrm{G}>\mathrm{A}$ & 2 & $0.003 \%$ \\
$\mathrm{c} .919-2 \mathrm{~A}>\mathrm{G} / \mathrm{c} .1229 \mathrm{C}>\mathrm{T}$ & 1 & $0.002 \%$ \\
$\mathrm{c} .919-2 \mathrm{~A}>\mathrm{G} / \mathrm{c} .1975 \mathrm{G}>\mathrm{C}$ & 2 & $0.003 \%$ \\
$\mathrm{c} .919-2 \mathrm{~A}>\mathrm{G} / \mathrm{c} .2027 \mathrm{~T}>\mathrm{A}$ & 2 & $0.003 \%$ \\
$\mathrm{c} .919-2 \mathrm{~A}>\mathrm{G} / \mathrm{c} .2168 \mathrm{~A}>\mathrm{G}$ & 4 & $0.01 \%$ \\
\hline Total & 1594 & $2.62 \%$
\end{tabular}

Note: This statistical data contains 41 cases that carry both SLC26A4 and other deafness gene variants.

397 
Table 4 Deafness gene variant of 1,746 spouses $^{\text {a }}$

\begin{tabular}{|c|c|c|c|}
\hline Detected genes & Variant types & Cases & Carrying rate \\
\hline & & & $(\mathrm{n}=1746)$ \\
\hline \multirow[t]{8}{*}{ GJB2 } & c. $109 \mathrm{G}>\mathrm{A}$ heterozygous variant & 38 & $2.18 \%$ \\
\hline & c. 235 delC heterozygous variant & 24 & $1.37 \%$ \\
\hline & c. $235 \mathrm{delC}$ homozygous variant & 3 & $0.17 \%$ \\
\hline & c.299_300delAT heterozygous variant & 9 & $0.52 \%$ \\
\hline & c. 35 delG heterozygous variant & 1 & $0.06 \%$ \\
\hline & c. $9 \mathrm{G}>\mathrm{A}$ heterozygous variant & 1 & $0.06 \%$ \\
\hline & c. $187 \mathrm{G}>\mathrm{T}$ heterozygous variant & 1 & $0.06 \%$ \\
\hline & others $^{1}$ & 5 & $0.29 \%$ \\
\hline \multirow[t]{9}{*}{ SLC26A4 } & c.919-2A $>$ G heterozygous variant & 16 & $0.92 \%$ \\
\hline & c.919-2A>G homozygous variant & 1 & $0.06 \%$ \\
\hline & c. $2168 \mathrm{~A}>\mathrm{G}$ heterozygous variant & 3 & $0.17 \%$ \\
\hline & c. $1226 \mathrm{G}>\mathrm{A}$ heterozygous variant & 2 & $0.11 \%$ \\
\hline & c. $1229 \mathrm{C}>\mathrm{T}$ heterozygous variant & 1 & $0.06 \%$ \\
\hline & c. $1975 \mathrm{G}>\mathrm{C}$ heterozygous variant & 1 & $0.06 \%$ \\
\hline & c. $1263+1 \mathrm{G}>\mathrm{A}$ heterozygous variant & 1 & $0.06 \%$ \\
\hline & c. $.563 \mathrm{~T}>\mathrm{C}$ heterozygous variant & 1 & $0.06 \%$ \\
\hline & c. $415+2 \mathrm{~T}>\mathrm{C}$ heterozygous variant & 1 & $0.06 \%$ \\
\hline
\end{tabular}


c.919-2A $>$ G/c. $1174 \mathrm{~A}>\mathrm{T}$ compound $\quad 1 \quad 0.06 \%$

heterozygous variant

c. $919-2 \mathrm{~A}>\mathrm{G} / \mathrm{c} .2168 \mathrm{~A}>\mathrm{G}$ compound $\quad 1 \quad 0.06 \%$

heterozygous variant

c. $919-2 \mathrm{~A}>\mathrm{G} / \mathrm{c} .1829 \mathrm{C}>\mathrm{A}$ compound $\quad 1 \quad 0.06 \%$

heterozygous variant

c.754T $>\mathrm{C} / \mathrm{c} .2168 \mathrm{~A}>\mathrm{G}$ compound $\quad 1 \quad 0.06 \%$

heterozygous variant

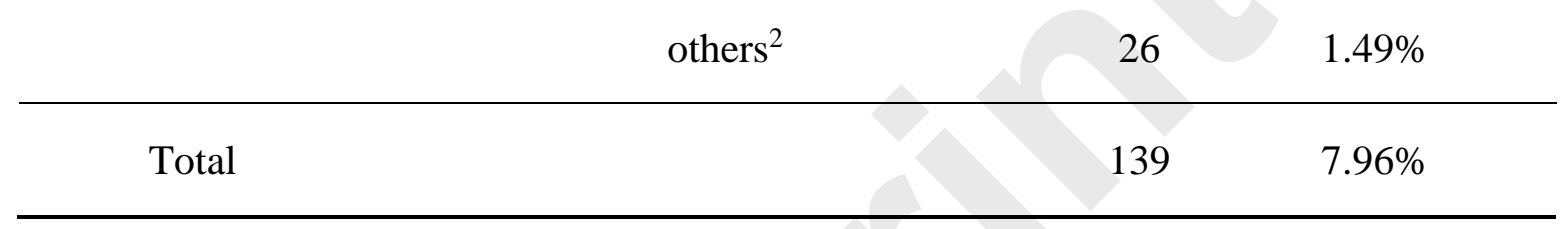

Table 5 Prenatal diagnosis results of 51 couples

Detected No. Female's deafness Male's deafness gene Prenatal diagnosis result of

\begin{tabular}{ccccc} 
genes & gene test result & test result & fetus \\
\hline GJB2 & 1 & c.235delC & c.235delC & c.235delC heterozygous variant
\end{tabular}

heterozygous variant heterozygous variant

2 c. $235 \mathrm{delC}$ c.235delC c. $235 \mathrm{delC}$ heterozygous variant

heterozygous variant heterozygous variant

3 c. $235 \mathrm{delC} \quad$ c.109G $>$ A c.235delC heterozygous variant 
heterozygous variant heterozygous variant

heterozygous variant heterozygous variant

heterozygous variant heterozygous variant

$\begin{array}{cc}\text { c.235delC } & \text { c.109G }>\mathrm{A} \\ \text { heterozygous variant } & \text { heterozygous variant }\end{array}$

heterozygous variant variant c.235delC c.35delG heterozygous

heterozygous variant variant

$$
\text { c.558_605Dup }
$$
c.235delC

heterozygous variant

$$
\text { c. } 235 \mathrm{delC}
$$

c.109G>A

Normal

heterozygous variant heterozygous variant

heterozygous variant heterozygous variant

$$
\text { c. } 235 \mathrm{delC}
$$

heterozygous variant heterozygous variant 
heterozygous variant heterozygous variant

heterozygous variant heterozygous variant

heterozygous variant heterozygous variant

$$
\text { c. } 235 \mathrm{delC}
$$

c.235delC

c. 235 delC homozygous variant

heterozygous variant heterozygous variant

heterozygous variant heterozygous variant

$$
\text { c. } 235 \mathrm{delC}
$$

c.299_300delAT heterozygous

heterozygous variant heterozygous variant

$$
\text { variant }
$$

$$
\text { c. } 235 \mathrm{delC}
$$

c. $235 \mathrm{delC}$

c.235delC homozygous variant

heterozygous variant heterozygous variant

heterozygous variant heterozygous variant

$$
\text { c. } 235 \mathrm{delC}
$$

c.235delC

Normal

heterozygous variant heterozygous variant

heterozygous variant heterozygous variant

$$
\text { c.235delC }
$$

c.235delC

c.235delC heterozygous variant

heterozygous variant heterozygous variant 
heterozygous variant heterozygous variant

heterozygous variant heterozygous variant

variant

variant

variant

variant

heterozygous variant heterozygous variant 


\begin{tabular}{|c|c|c|c|c|}
\hline & & & & variant \\
\hline & 35 & c.299_300delAT & c.235del heterozygous & c.299_300delAT/c.235delC \\
\hline & & heterozygous variant & variant & compound heterozygous \\
\hline & & & & variant \\
\hline & 36 & c.299_300delAT & c.235del heterozygous & c.299_300delAT/c.235delC \\
\hline & & heterozygous variant & variant & compound heterozygous \\
\hline & & & & variant \\
\hline SLC26A4 & 37 & c. $1174 \mathrm{~A}>\mathrm{T}$ & c. $487 \mathrm{G}>\mathrm{C}$ & c. $487 \mathrm{G}>\mathrm{C}$ heterozygous variant \\
\hline & & heterozygous variant & heterozygous variant & \\
\hline & 38 & c. $1226 \mathrm{G}>\mathrm{A}$ & c. $919-2 A>G$ & Normal \\
\hline & & heterozygous variant & heterozygous variant & \\
\hline & 39 & c. $919-2 A>G$ & c. $919-2 \mathrm{~A}>\mathrm{G} / \mathrm{c} .1829 \mathrm{C}>$ & c. $919-2 \mathrm{~A}>\mathrm{G}$ heterozygous \\
\hline & & heterozygous variant & A compound & variant \\
\hline & 40 & c. $919-2 A>G$ & c. $919-2 A>G$ & Normal \\
\hline & & heterozygous variant & heterozygous variant & \\
\hline & 41 & c. $919-2 A>G$ & c. $1975 \mathrm{G}>\mathrm{C}$ & c. $919-2 \mathrm{~A}>\mathrm{G}$ heterozygous \\
\hline & & heterozygous variant & heterozygous variant & variant \\
\hline & 42 & c. $919-2 A>G$ & c. $919-2 A>G$ & Normal \\
\hline & & heterozygous variant & heterozygous variant & \\
\hline & 43 & c. $919-2 A>G$ & c. $919-2 A>G$ & Normal \\
\hline & & heterozygous variant & heterozygous variant & \\
\hline
\end{tabular}




$$
\text { c. } 919-2 \mathrm{~A}>\mathrm{G}
$$

c. $2168 \mathrm{~A}>\mathrm{G}$

Normal

heterozygous variant heterozygous variant

45

$$
\text { c.919-2A>G }
$$

c. $919-2 \mathrm{~A}>\mathrm{G}$

heterozygous variant heterozygous variant

46

$$
\text { c. } 919-2 \mathrm{~A}>\mathrm{G}
$$

$$
\text { c. } 919-2 \mathrm{~A}>\mathrm{G}
$$

heterozygous variant heterozygous variant

47

48 c. $919-2 \mathrm{~A}>\mathrm{G}$

heterozygous variant heterozygous variant c. $919-2 A>G$

c.919-2A>G

heterozygous variant heterozygous variant

$$
\text { c. } 589 \mathrm{G}>\mathrm{A}
$$

c. $919-2 \mathrm{~A}>\mathrm{G}$

heterozygous variant heterozygous variant

heterozygous variant heterozygous variant

heterozygous variant heterozygous variant
Normal

c. $919-2 \mathrm{~A}>\mathrm{G}$ heterozygous

variant 
No. Children's Deafnes Children's deafness gene test Mother's deafness Father's corre hearing test $\mathrm{s}$ genes $\quad$ gesults test results deafness results sequencing

Left ear Right

ear

$1 \quad 60 \mathrm{dBnH} 70 \mathrm{dBnH} \quad$ GJB2

c.299_300delAT Heterozygous

c.299_300delAT

Undor

L L

variation

heterozygous

variation

2 No No

c.235delC/ c.299_300delAT

c. $235 \mathrm{delC}$

c. $299 \_300$

compound heterozygous variation

heterozygous

heterozygous

variation

3 No No

c.235delC/ c.299_300delAT

c.235delC

c.299_300

compound heterozygous variation

heterozygous

heterozygous

variation

$460 \mathrm{dBnH} 60 \mathrm{dBnH}$

c.235delC homozygous compound

c. $235 \mathrm{delC}$

Undon

L L

heterozygous variant

$530 \mathrm{dBnH} 60 \mathrm{dBnH}$

c.109G>A /c.299_300delAT

c.299_300delAT

c. $109 \mathrm{G}$

L L

heterozygous variation

heterozygous variant heterozygou

6 No $30 \mathrm{dBnH}$

c. 235 delC heterozygous variant

c. $235 \mathrm{delC}$

c.608T;

L

heterozygous variant heterozygous

$7 \quad$ No No

c.9G>A/c.235delC compound

c. $235 \mathrm{delC}$

c.9G $>$ A heter

heterozygous variant

heterozygous variant

varian 
$8 \quad$ No $\quad$ No

c.299_300delAT homozygous

c.299_300delAT

c.299_300

compound

heterozygous variant heterozygou

$990 \mathrm{dBnH} 90 \mathrm{dBnH}$

c.235delC/ c.299_300delAT

c.299_300delAT

c. $235 \mathrm{~d}$

L L

compound heterozygous variant heterozygous variant heterozygous

10 No No

c.235delC homozygous compound

c. $235 \mathrm{delC}$

Undon

heterozygous variant

11 100dBn 80dBnH SLC26

c. $919-2 \mathrm{~A}>\mathrm{G} / \mathrm{c} .2168 \mathrm{~A}>\mathrm{G}$

c. $919-2 \mathrm{~A}>\mathrm{G} / \mathrm{c} .2168$

c.919-2A

HL L $\quad A 4 \quad$ compound heterozygous variant

$\mathrm{A}>\mathrm{G}$ compound heterozygous

heterozygous variant

12 No No

c.919-2A>G homozygous

compound

c.919-2A $>$ G homozygous

L L

$14 \quad$ No $30 \mathrm{dBnH}$

L

$15 \quad$ No $90 \mathrm{dBnH}$

$\mathrm{L}$

$1670 \mathrm{dBnH} 30 \mathrm{dBnH}$

$\mathrm{L}$

$\mathrm{L}$

c.919-2A>G homozygous

compound

c. $1975 \mathrm{G}>\mathrm{C}$ heterozygous variant

$1730 \mathrm{dBnH} \quad$ No

Normal

$\mathrm{L}$

$1860 \mathrm{dBnH} 60 \mathrm{dBnH}$ c. 235 delC heterozygous variant c. $1975 \mathrm{G}>\mathrm{C}$

heterozygous variant

c. $919-2 A>G$

Undon

heterozygous variant

c. $919-2 A>G$

Undon

heterozygous variant

c. $919-2 A>G$

Undon

heterozygous variant

$$
\text { c. } 919-2 \mathrm{~A}>\mathrm{G}
$$

Undon

heterozygous variant

c. $235 \mathrm{delC}$

Undon

heterozygous variant

$$
\text { c. } 235 \mathrm{delC}
$$

Undon 
L L

$1950 \mathrm{dBnH} 60 \mathrm{dBnH}$

L L

20 80dBnH 70dBnH

L L

$2170 \mathrm{dBnH}$ 80dBnH

L L heterozygous variant

Undone

c. $235 \mathrm{delC}$

Undon

heterozygous variant

Undone

c.235delC

Undon

heterozygous variant

Undone

c. $919-2 \mathrm{~A}>\mathrm{G}$

Undon
402

403

404

405

406

407

408

409

410

411

412

413
Figure 1 Research procedures 


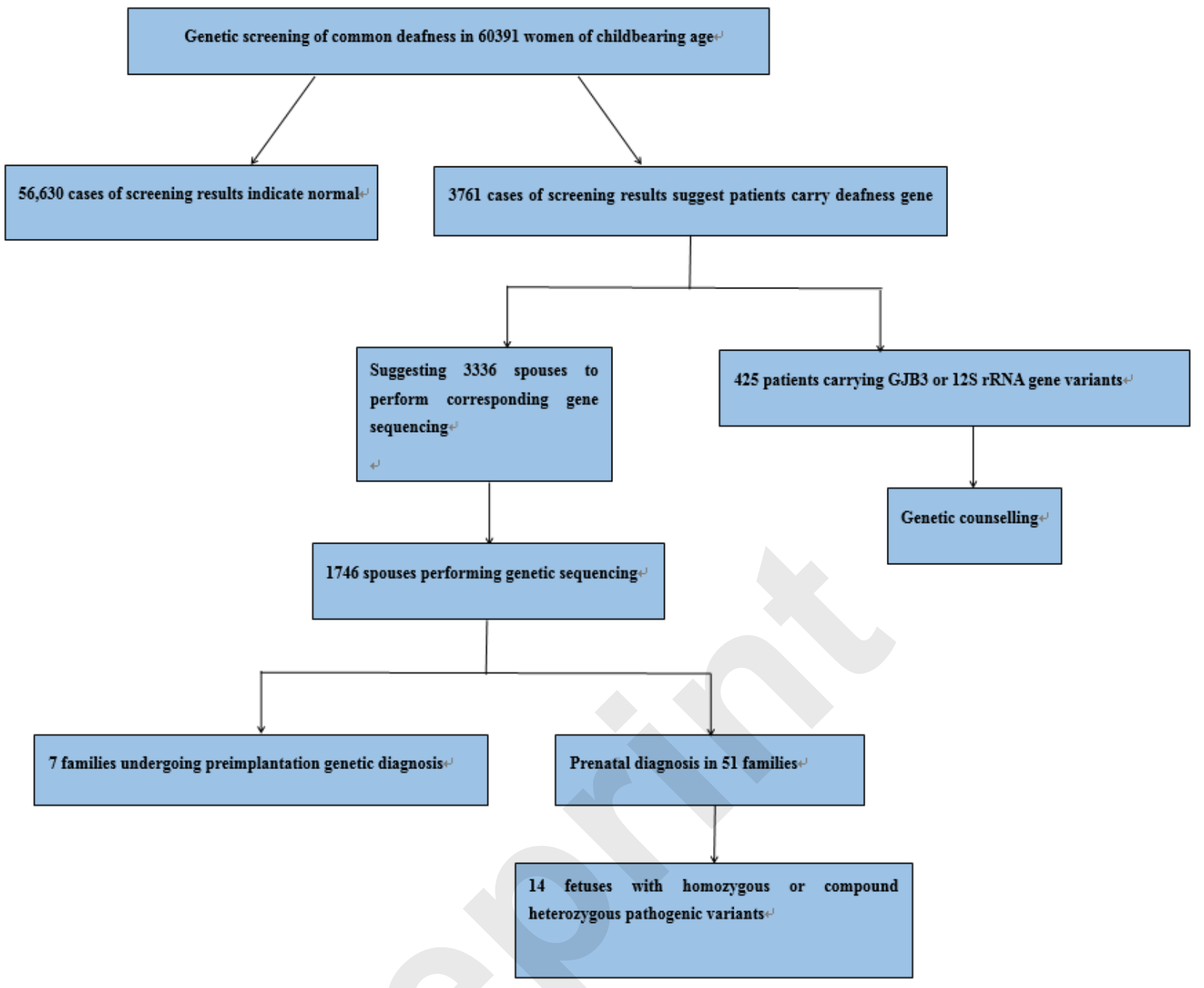


Table 1 Common deafness gene screening results of 60,391 cases

\begin{tabular}{cccc}
\hline Variant types & Cases & $\begin{array}{c}\text { Carrying rate } \\
(\mathrm{n}=3761)\end{array}$ & $\begin{array}{c}\text { Carrying rate } \\
(\mathrm{n}=60391)\end{array}$ \\
\hline I2S rRNA 1555A>G homogenous variant & 97 & $2.58 \%$ & $0.16 \%$ \\
I2S rRNA 1555A>G heterogenous variant & 21 & $0.56 \%$ & $0.03 \%$ \\
I2S rRNA 1494C>T homogenous variant & 7 & $0.19 \%$ & $0.01 \%$ \\
GJB2 homozygous variant & 9 & $0.24 \%$ & $0.01 \%$ \\
GJB2 compound heterozygous variant & 6 & $0.16 \%$ & $0.01 \%$ \\
SLC26A4 homozygous variant & 5 & $0.13 \%$ & $0.01 \%$ \\
SLC26A4 compound heterozygous variant & 14 & $0.37 \%$ & $0.02 \%$ \\
\hline Total 1 & 159 & $4.23 \%$ & $0.26 \%$ \\
\hline GJB2 heterozygous variant & 1724 & $45.84 \%$ & $2.85 \%$ \\
SLC26A4 heterozygous variant & 1534 & $40.79 \%$ & $2.54 \%$ \\
GJB3 compound heterozygous variant & 300 & $7.98 \%$ & $0.50 \%$ \\
Combined heterozygous variants in GJB2 and & 38 & $1.01 \%$ & $0.06 \%$ \\
SLC26A4 & & & \\
Combined heterozygous variants in GJB2 and GJB3 & 3 & $0.08 \%$ & $0.005 \%$ \\
Combined heterozygous variants in SLC26A4 and & 3 & $0.08 \%$ & $0.005 \%$ \\
GJB3 & & & \\
\hline Total 2 & 3602 & $95.77 \%$ & $5.96 \%$ \\
\hline Total (1+2) & 3761 & $100.00 \%$ & $6.23 \%$ \\
\hline
\end{tabular}

Note: The statistical results do not include polymorphic sites in gene. $n=60391$, pre-pregnancy/ early-pregnancy women. $n=3761$, women carried common deafness gene variants.

Table 2 GJB2 variant types and variant sites in 60391 cases

\begin{tabular}{cccc}
\hline Variant types & Variant sites & Cases & $\begin{array}{c}\text { Carrying rate } \\
(\mathrm{n}=60391)\end{array}$ \\
\hline Homozygous variant & c.235delC & 6 & $0.01 \%$ \\
Heterozygous variant & c.299_300delAT & 3 & $0.005 \%$ \\
& c.176_191del16 & 65 & $0.11 \%$ \\
& c.235delC & 1257 & $2.06 \%$ \\
Compound & c.299_300delAT & 440 & $0.72 \%$ \\
heterozygous variant & c.35delG & 3 & $0.005 \%$
\end{tabular}




\begin{tabular}{cccc} 
& c.235delC/c.299_300delAT & 5 & $0.01 \%$ \\
\hline Total & 1780 & $2.92 \%$ \\
\hline
\end{tabular}

Note: This statistical data contains 41 cases that carry both GJB2 and other deafness gene variants.

Table 3 SLC26A4 variant types and variant sites in 60391 cases

\begin{tabular}{|c|c|c|c|}
\hline Variant types & Variant sites & Cases & $\begin{array}{c}\text { Carrying rate } \\
(\mathrm{n}=60391)\end{array}$ \\
\hline \multirow[t]{2}{*}{ Homozygous variant } & c. $1229 \mathrm{C}>\mathrm{T}$ & 1 & $0.00 \%$ \\
\hline & c. $919-2 A>G$ & 4 & $0.01 \%$ \\
\hline \multirow[t]{10}{*}{ Heterozygous variant } & c. $1174 \mathrm{~A}>\mathrm{T}$ & 114 & $0.19 \%$ \\
\hline & c. $1226 \mathrm{G}>\mathrm{A}$ & 46 & $0.08 \%$ \\
\hline & c. $1229 \mathrm{C}>\mathrm{T}$ & 75 & $0.12 \%$ \\
\hline & c. $1975 \mathrm{G}>\mathrm{C}$ & 136 & $0.23 \%$ \\
\hline & c. $2027 \mathrm{~T}>\mathrm{A}$ & 31 & $0.05 \%$ \\
\hline & c. $2168 \mathrm{~A}>\mathrm{G}$ & 248 & $0.41 \%$ \\
\hline & c. $281 \mathrm{C}>\mathrm{T}$ & 5 & $0.01 \%$ \\
\hline & c. $589 \mathrm{G}>\mathrm{A}$ & 27 & $0.04 \%$ \\
\hline & c. $1707+5 \mathrm{G}>\mathrm{A}$ & 16 & $0.03 \%$ \\
\hline & c. $919-2 A>G$ & 877 & $1.45 \%$ \\
\hline \multirow{7}{*}{$\begin{array}{c}\text { Compound heterozygous } \\
\text { variant }\end{array}$} & c. $1174 \mathrm{~A}>\mathrm{T} / \mathrm{c} .1226 \mathrm{G}>\mathrm{A}$ & 1 & $0.002 \%$ \\
\hline & c. $919-2 \mathrm{~A}>\mathrm{G} / \mathrm{c} .1174 \mathrm{~A}>\mathrm{T}$ & 2 & $0.003 \%$ \\
\hline & c. $919-2 \mathrm{~A}>\mathrm{G} / \mathrm{c} .1226 \mathrm{G}>\mathrm{A}$ & 2 & $0.003 \%$ \\
\hline & c. $919-2 \mathrm{~A}>\mathrm{G} / \mathrm{c} .1229 \mathrm{C}>\mathrm{T}$ & 1 & $0.002 \%$ \\
\hline & c. $919-2 \mathrm{~A}>\mathrm{G} / \mathrm{c} .1975 \mathrm{G}>\mathrm{C}$ & 2 & $0.003 \%$ \\
\hline & c. $919-2 \mathrm{~A}>\mathrm{G} / \mathrm{c} .2027 \mathrm{~T}>\mathrm{A}$ & 2 & $0.003 \%$ \\
\hline & c. $919-2 \mathrm{~A}>\mathrm{G} / \mathrm{c} .2168 \mathrm{~A}>\mathrm{G}$ & 4 & $0.01 \%$ \\
\hline Total & & 1594 & $2.62 \%$ \\
\hline
\end{tabular}

Note: This statistical data contains 41 cases that carry both SLC26A4 and other deafness gene variants. 
Table 4 SLC26A4 and GJB2 variant of 1,746 spouses ${ }^{\text {a }}$

\begin{tabular}{|c|c|c|c|}
\hline Detected genes & Variant types & Cases & $\begin{array}{l}\text { Carrying rate } \\
\qquad(\mathrm{n}=1746)\end{array}$ \\
\hline \multirow[t]{8}{*}{ GJB2 } & c. $109 \mathrm{G}>\mathrm{A}$ heterozygous variant & 38 & $2.18 \%$ \\
\hline & c. 235 delC heterozygous variant & 24 & $1.37 \%$ \\
\hline & c. 235 delC homozygous variant & 3 & $0.17 \%$ \\
\hline & c. 299_300delAT heterozygous variant & 9 & $0.52 \%$ \\
\hline & c. 35 delG heterozygous variant & 1 & $0.06 \%$ \\
\hline & c. $9 \mathrm{G}>\mathrm{A}$ heterozygous variant & 1 & $0.06 \%$ \\
\hline & c. $187 \mathrm{G}>\mathrm{T}$ heterozygous variant & 1 & $0.06 \%$ \\
\hline & others $^{1}$ & 5 & $0.29 \%$ \\
\hline \multirow[t]{14}{*}{ SLC26A4 } & c. $919-2 A>G$ heterozygous variant & 16 & $0.92 \%$ \\
\hline & c. 919-2A $>\mathrm{G}$ homozygous variant & 1 & $0.06 \%$ \\
\hline & c. $2168 \mathrm{~A}>\mathrm{G}$ heterozygous variant & 3 & $0.17 \%$ \\
\hline & c. $1226 G>A$ heterozygous variant & 2 & $0.11 \%$ \\
\hline & c. $1229 \mathrm{C}>\mathrm{T}$ heterozygous variant & 1 & $0.06 \%$ \\
\hline & c. $1975 G>C$ heterozygous variant & 1 & $0.06 \%$ \\
\hline & c. $1263+1 G>A$ heterozygous variant & 1 & $0.06 \%$ \\
\hline & c. $563 \mathrm{~T}>\mathrm{C}$ heterozygous variant & 1 & $0.06 \%$ \\
\hline & c. $415+2 \mathrm{~T}>\mathrm{C}$ heterozygous variant & 1 & $0.06 \%$ \\
\hline & c. $919-2 A>G /$ c. $1174 A>T$ compound heterozygous & 1 & $0.06 \%$ \\
\hline & $\begin{array}{c}\text { c. } 919-2 A>G / \text { c. } 2168 A>G \text { compound heterozygous } \\
\text { variant }\end{array}$ & 1 & $0.06 \%$ \\
\hline & $\begin{array}{c}\text { c. } 919-2 A>G / \text { c. } 1829 \mathrm{C}>\mathrm{A} \text { compound heterozygous } \\
\text { variant }\end{array}$ & 1 & $0.06 \%$ \\
\hline & $\begin{array}{c}\text { c. } 754 \mathrm{~T}>\mathrm{C} / \mathrm{c} .2168 \mathrm{~A}>\mathrm{G} \text { compound heterozygous } \\
\text { variant }\end{array}$ & 1 & $0.06 \%$ \\
\hline & others $^{2}$ & 26 & 1. $49 \%$ \\
\hline Total & & 139 & $7.96 \%$ \\
\hline
\end{tabular}

Note: $\mathrm{n}=1746$, women' $\mathrm{s}$ spouses

Table 5 Prenatal diagnosis results of 51 couples

Detected No. Female' s gene test Male' s gene test result Prenatal diagnosis result of genes result fetus 
GJB2 1 c. 235delC heterozygous c. 235delC heterozygous c. 235 delC heterozygous variant variant variant

2 c. 235 delC heterozygous c. 235 delC heterozygous c. 235 delC heterozygous variant variant variant

3 c. 235 delC heterozygous c. $109 \mathrm{G}>\mathrm{A}$ heterozygous c. 235 delC heterozygous variant variant variant

4 c. 235 delC heterozygous c. 109G>A heterozygous Normal variant variant

5 c. 235delC heterozygous c. 299_300delAT c.235de1C/c.299_300delAT variant heterozygous variant compound heterozygous variant

6 c. 235 de1C c. 109G $>$ A heterozygous c. 235de1C/c. 109G $>$ A compound heterozygous variant variant heterozygous variant

7 c. 235 delC heterozygous c. 35 delG heterozygous c. 235 deLC heterozygous variant variant variant

8 c. 235 delC heterozygous c. 35 delG heterozygous c. 235 deLC heterozygous variant variant variant

9 c. 235 delC heterozygous

c. 558_605Dup

Normal variant

10 c. 235 delC heterozygous

c. $109 \mathrm{G}>\mathrm{A}$ heterozygous

Norma1 variant variant

11 c. 235delC heterozygous c. 299_300de1AT

c. 235delC heterozygous variant variant heterozygous variant

12 c. 235 delC heterozygous c. 235 delC heterozygous c. 235 delC heterozygous variant variant variant

13 c. 235 delC heterozygous c. 235 delC heterozygous c. 235 delC heterozygous variant variant variant

14 c. 235 delC heterozygous c. 235 delC heterozygous c. 235 delC heterozygous variant variant variant

15 c. 235 delC heterozygous c. 235 delC heterozygous

Norma1 variant variant

16 c. 235 delC heterozygous c. 235 delC heterozygous

c. 235 delC homozygous variant variant variant

17 c. 235 delC heterozygous c. 235 delC heterozygous c. 235 delC homozygous variant variant variant

18 c. 235 delC heterozygous

c. 299_300de1AT variant heterozygous variant

19 c. 235 delC heterozygous c. 235 delC heterozygous variant variant

20 c. 235 delC heterozygous c. 235 delC heterozygous variant variant

21 c. 235 delC heterozygous c. 235 delC heterozygous variant variant

c. 299_300de1AT heterozygous variant

c. 235 delC homozygous variant c. 235 delC homozygous variant

Norma1 c. 235 delC heterozygous c. 235 delC heterozygous c. 235 delC heterozygous variant 
variant variant

23 c. 235 delC heterozygous c. 235 delC heterozygous c. 235 delC heterozygous variant variant variant

24 c. 235 delC heterozygous variant

variant variant variant variant variant

$$
\text { c. 299_300delAT }
$$

heterozygous variant

c. 299_300de1AT heterozygous variant

c. 299_300delAT heterozygous variant

$$
\text { c. 299_300delAT }
$$

heterozygous variant

$$
\text { c. 299_300de1AT }
$$

heterozygous variant

$$
\text { c. 299_300delAT }
$$

heterozygous variant

c. 299_300delAT

heterozygous variant

c. 299_300delAT heterozygous variant

$$
\text { c. 299_300delAT }
$$

heterozygous variant

c. 299_300de1AT heterozygous variant

$$
\text { c. 299_300de1AT }
$$
heterozygous variant

$$
\text { c. 299_300de1AT }
$$

heterozygous variant

\section{c. 235 del heterozygous} variant

c. $487 \mathrm{G}>\mathrm{C}$ heterozygous variant variant

c. 299_300delAT heterozygous variant c. 235del heterozygous variant

c. 235del heterozygous variant

c. 235 del heterozygous variant

c. 109G>A heterozygous variant

c. 109G>A heterozygous variant

c. $187 \mathrm{G}>\mathrm{T}$ heterozygous variant

c. 299_300de1AT

heterozygous variant c. $230 \mathrm{G}>\mathrm{A}$ heterozygous variant

c. 235 del heterozygous variant

c. 235del heterozygous variant c. 235 delC heterozygous variant heterozygous variant

$2 \mathrm{~A}>\mathrm{G}$ heterozygous

variant

c. 919-2A $>\mathrm{G}$ heterozygous $\quad$ c. 919-2A $>\mathrm{G} /$ c. $1829 \mathrm{C}>\mathrm{A} \quad$ c. 919-2A $>\mathrm{G}$ heterozygous variant compound heterozygous

variant

0 c. 919-2A $>\mathrm{G}$ heterozygous c. 919-2A $>\mathrm{G}$ heterozygous

variant

1 c. 919-2A $>$ G heterozygous c. $1975 \mathrm{G}>\mathrm{C}$ heterozygous c. 919-2A $>\mathrm{G}$ heterozygous variant variant

c. $919-2 \mathrm{~A}>\mathrm{G}$ heterozygous c. $919-2 \mathrm{~A}>\mathrm{G}$ heterozygous variant c. 919-2A $>\mathrm{G}$ heterozygous c. 919-2A $>\mathrm{G}$ heterozygous c. 299_300delAT homozygous variant

c. 299_300delAT heterozygous variant

Normal

Normal

c. 109G>A/c. 299 300delAT compound heterozygous variant c. $109 \mathrm{G}>\mathrm{A}$ heterozygous variant c. $187 \mathrm{G}>\mathrm{T}$ heterozygous variant c. 299_300delAT homozygous variant

c. 299_300delAT heterozygous variant

c. 235de1C/c. 299-300de1AT compound heterozygous variant

c. 299_300de1AT/c. 235de1C compound heterozygous variant

c. 299 300delAT/c. 235delC compound heterozygous variant c. $487 G>C$ heterozygous variant

Normal

Normal

Norma1 
variant variant

44 c. 919-2A>G heterozygous c. $2168 \mathrm{~A}>\mathrm{G}$ heterozygous Normal

variant variant

45 c. 919-2A $>\mathrm{G}$ heterozygous c. 919-2A $>\mathrm{G}$ heterozygous c. 919-2A $>\mathrm{G}$ heterozygous variant variant variant

46 c. 919-2A $>$ G heterozygous c. 919-2A $>$ G heterozygous Normal variant variant

47 c. 919-2A $>\mathrm{G}$ heterozygous c. 919-2A $>\mathrm{G}$ heterozygous c. 919-2A $>\mathrm{G}$ homozygous variant variant variant

48 c. 919-2A $>\mathrm{G}$ heterozygous c. 919-2A $>\mathrm{G}$ heterozygous c. 919-2A $>\mathrm{G}$ heterozygous variant variant variant

49 c. $589 \mathrm{G}>\mathrm{A}$ heterozygous c. 919-2A $>\mathrm{G}$ heterozygous c. 919-2A $>\mathrm{G}$ heterozygous variant variant variant

50 c. $1975 \mathrm{G}>\mathrm{C}$ heterozygous c. $1226 \mathrm{G}>\mathrm{A}$ heterozygous $\quad$ c. $1975 \mathrm{G}>\mathrm{C} / \mathrm{c} .1226 \mathrm{G}>\mathrm{A}$ compound variant variant heterozygous variant

51 c. $1975 G>C$ heterozygous c. 919-2A $>$ G heterozygous Normal variant variant

Table 6 Confirmed children with hearing and deafness gene test results

\begin{tabular}{|c|c|c|c|c|c|c|}
\hline No. & $\begin{array}{l}\text { Children' } \\
\text { test } r \\
\text { Left ear }\end{array}$ & $\begin{array}{l}\text { s hearing } \\
\text { esults } \\
\text { Right ear }\end{array}$ & $\begin{array}{l}\text { Deafness } \\
\text { genes }\end{array}$ & Children's deafness gene test results & $\begin{array}{l}\text { Mother's deafness gene } \\
\text { test results }\end{array}$ & $\begin{array}{c}\text { Father's corresponding } \\
\text { deafness gene sequencing } \\
\text { results }\end{array}$ \\
\hline 1 & $60 \mathrm{dBnHL}$ & $70 \mathrm{dBnHL}$ & GJB2 & c. 299_300delAT Heterozygous variation & $\begin{array}{c}\text { c. } 299 \_300 \text { delAT } \\
\text { heterozygous variation }\end{array}$ & Undone \\
\hline 2 & No & No & & $\begin{array}{c}\text { c. 235delC/ c.299_300delAT compound } \\
\text { heterozygous variation }\end{array}$ & $\begin{array}{l}\text { c. 235delC heterozygous } \\
\text { variation }\end{array}$ & $\begin{array}{l}\text { c. 299_300delAT } \\
\text { heterozygous variant }\end{array}$ \\
\hline 3 & No & No & & $\begin{array}{c}\text { c.235delC/ c. 299_300de1AT compound } \\
\text { heterozygous variation }\end{array}$ & $\begin{array}{l}\text { c. 235delC heterozygous } \\
\text { variation }\end{array}$ & $\begin{array}{l}\text { c. 299_300de1AT } \\
\text { heterozygous variant }\end{array}$ \\
\hline 4 & $60 \mathrm{dBnHL}$ & $60 \mathrm{dBnHL}$ & & c. 235delC homozygous compound & $\begin{array}{c}\text { c. 235delC heterozygous } \\
\text { variant }\end{array}$ & Undone \\
\hline 5 & 30dBnHL & $60 \mathrm{dBnHL}$ & & $\begin{array}{c}\text { c. 109G>A /c. 299_300delAT heterozygous } \\
\text { variation }\end{array}$ & $\begin{array}{c}\text { c. 299_300delAT } \\
\text { heterozygous variant }\end{array}$ & $\begin{aligned} \text { c. } 109 \mathrm{G}>\mathrm{A} \text { heterozygous } \\
\text { variant }\end{aligned}$ \\
\hline 6 & No & $30 \mathrm{dBnHL}$ & & c. 235 delC heterozygous variant & $\begin{array}{c}\text { c. 235delC heterozygous } \\
\text { variant }\end{array}$ & $\begin{array}{c}\text { c. } 608 \mathrm{~T}>\mathrm{C} \text { heterozygous } \\
\text { variant }\end{array}$ \\
\hline 7 & No & No & & $\begin{array}{c}\text { c. 9G>A/c. 235de1C compound heterozygous } \\
\text { variant }\end{array}$ & $\begin{array}{c}\text { c. 235delC heterozygous } \\
\text { variant }\end{array}$ & $\begin{array}{c}\text { c. } 9 \mathrm{G}>\mathrm{A} \text { heterozygous } \\
\text { variant }\end{array}$ \\
\hline 8 & No & No & & c. 299_300delAT homozygous compound & c. 299_300de1AT & c. 299_300delAT \\
\hline 9 & $90 \mathrm{dBnHL}$ & $90 \mathrm{dBnHL}$ & & $\begin{array}{c}\text { c.235de1C/ c.299_300delAT compound } \\
\text { heterozygous variant }\end{array}$ & $\begin{array}{l}\text { heterozygous variant } \\
\text { c. } 299 \_300 \text { delAT } \\
\text { heterozygous variant }\end{array}$ & $\begin{array}{c}\text { heterozygous variant } \\
\text { c. 235delC heterozygous } \\
\text { variant }\end{array}$ \\
\hline
\end{tabular}


variant

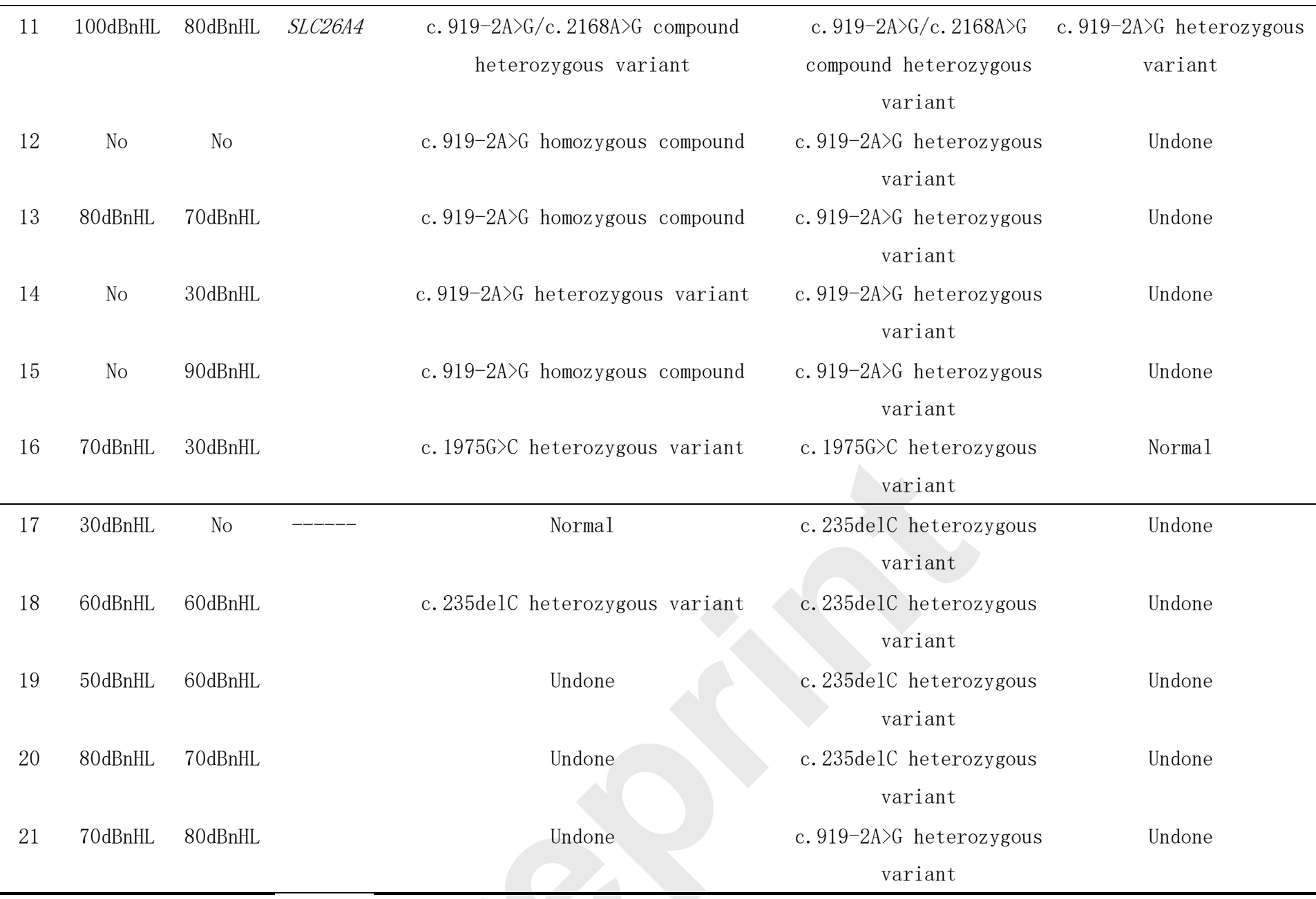

